\title{
$8 q 24$ amplified segments involve novel fusion genes between NSMCE2 and long noncoding RNAs in acute myelogenous leukemia
}

\author{
Yoshiaki Chinen ${ }^{1 \dagger}$, Natsumi Sakamoto ${ }^{1 \dagger}$, Hisao Nagoshi ${ }^{1}$, Tomohiko Taki $^{2}$, Saori Maegawa', Shotaro Tatekawa', \\ Taku Tsukamoto ${ }^{1}$, Shinsuke Mizutani ${ }^{1}$, Yuji Shimura ${ }^{1}$, Mio Yamamoto-Sugitani ${ }^{1}$, Tsutomu Kobayashi ${ }^{1}$, \\ Yosuke Matsumoto ${ }^{1}$, Shigeo Horiike ${ }^{1}$, Junya Kuroda ${ }^{1 *}$ and Masafumi Taniwaki ${ }^{1}$
}

\begin{abstract}
The pathogenetic roles of 8q24 amplified segments in leukemic cells with double minute chromosomes remain to be verified. Through comprehensive molecular analyses of 8q24 amplicons in leukemic cells from an acute myelogenous leukemia (AML) patient and AML-derived cell line HL60 cells, we identified two novel fusion genes between NSMCE2 and long noncoding RNAs (InCRNAs), namely, PVT1-NSMCE2 and BF104016-NSMCE2. Our study suggests that 8q24 amplicons are associated with the emergence of aberrant chimeric genes between NSMCE2 and oncogenic IncRNAs, and also implicate that the chimeric genes involving IncRNAs potentially possess as-yet-unknown oncogenic functional roles.
\end{abstract}

Keywords: Acute myeloid leukemia (AML), Long noncoding RNAs (lincRNAs), PVT1, NSMCE2, CCDC26

\section{To the Editor,}

To gain insight into the role(s) of double minute chromosomes (dmins) in leukemia, we cytogenetically/molecularly analyzed 8q24 amplicons in patient-derived leukemic cells and AML-derived cell line (HL60) (See Additional file 1 for supplementary materials and methods). The patient was a 71-year-old female with AML (M2). The G-banding karyotype of leukemic cells was $47, \mathrm{XX},+$ mar [2]/48, XX, idem, +mar [6]/46, XX [7], containing two marker chromosomes (mars) from chromosome 8 (Figure 1a and b). DNA copy number analysis (CNA) revealed 13 high-level amplicons on 8q22.1-q24.2 (98.43 Mb-134.16 Mb) (Additional file 2: Table S1). SKY analysis of HL60 cells containing the 8q24 amplicons revealed that the representative karyotype was 44, $\mathrm{X}, \operatorname{der}(5) \mathrm{t}(5 ; 17)(\mathrm{q} 11.2 ; \mathrm{q} 11.2), \mathrm{t}(7 ; 16 ; 9)(\mathrm{q} 34 ; \mathrm{q} 24 ; \mathrm{p} 21), \mathrm{t}(9 ; 14)$ (q22;q22), +13, -15, -17, der(21)t(15;21)(q22;q21) [1]. CNA revealed several amplicons on 8q24.13-q24.12 (126.25 Mb$130.75 \mathrm{Mb}$ ) in the HL60 cells (Figure 2a and b).

\footnotetext{
* Correspondence: junkuro@koto.kpu-m.ac.jp

${ }^{\dagger}$ Equal contributors

'Division of Hematology and Oncology, Department of Medicine, Kyoto Prefectural University of Medicine, Graduate School of Medical Science, 465 Kajii-choKamigyo-ku, Kyoto 602-8566, Japan

Full list of author information is available at the end of the article
}

Consequently, three common amplicons were identified between 8q24.13-21 in the patient and the HL60 cells; i.e., the regions covering NSMCE2 (8q24.13), PVT1 (8q24.21) and $C C D C 26$ (8q24.21) (Figures 1c and 2b). Further investigation revealed three fusion transcripts between $P V T 1$ exon 1a and NSMCE2 exon 3 in the patient (Figure 1d and e), and a fusion gene between exon 6 of NSMCE2 and exon 1 of BF104016, a noncoding RNA sharing the sequence of $C C D C 26$ exon 4 (Additional file 3: Figure S1) (Additional file 4: Table S2), in the HL60 cells (Figure 2c-e). Both the NSMCE2 and PVT1 genes were amplified and located in a micronucleus in the patient (Figure 1f-i), and the genomic junction of 5'-PVT1-NSMCE2-3' was located within intron 1 of PVT1 and at 5' upstream of exon 1 of NSMCE2 (Figure $1 \mathrm{j}$ and $\mathrm{k}$ ) (Additional file 5: Figure S3). In the HL60 cells, amplification of $3^{\prime} N S M C E 2$ and ${ }^{\prime} C C D C 26$ was colocalized on $\operatorname{der}(13) \mathrm{hsr}(8)$, ins(2;8) and dmins (Figure 2e-h) (Additional file 5: Figure S3). Aberrant NSMCE2 transcripts were higher than normal NSMCE2 transcripts in the patient and the HL60 cells, while NSMCE2 protein expression did not correlate with normal or abnormal NSMCE2 transcripts among the leukemic patient cells or the HL60 cells, suggesting the presence of regulatory mechanisms other than transcription (Additional file 6: Figure S2). 


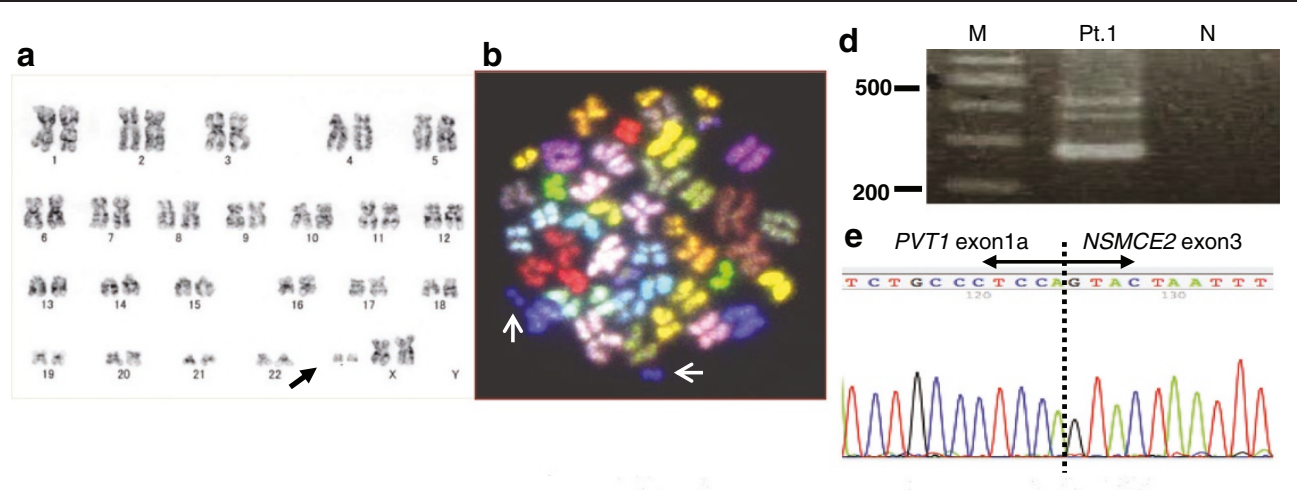

c
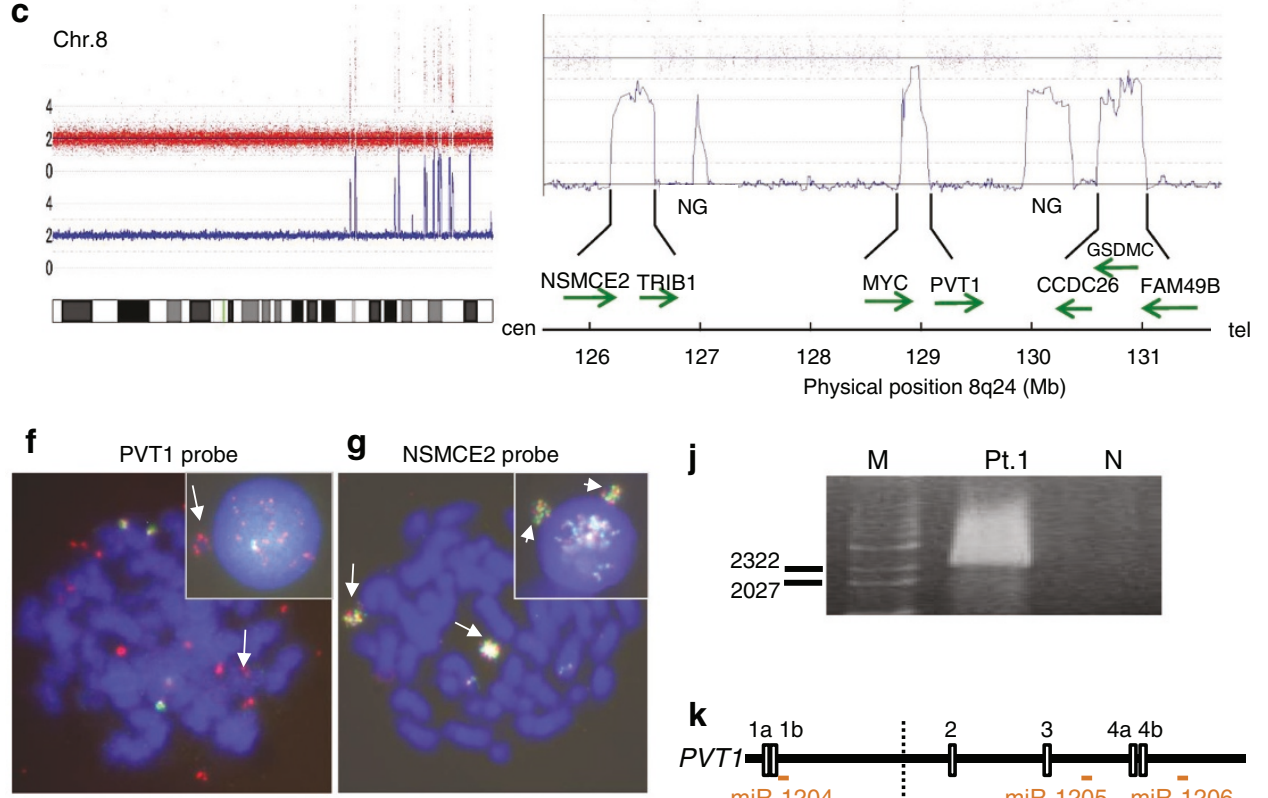

h

i NSMCE2 probe
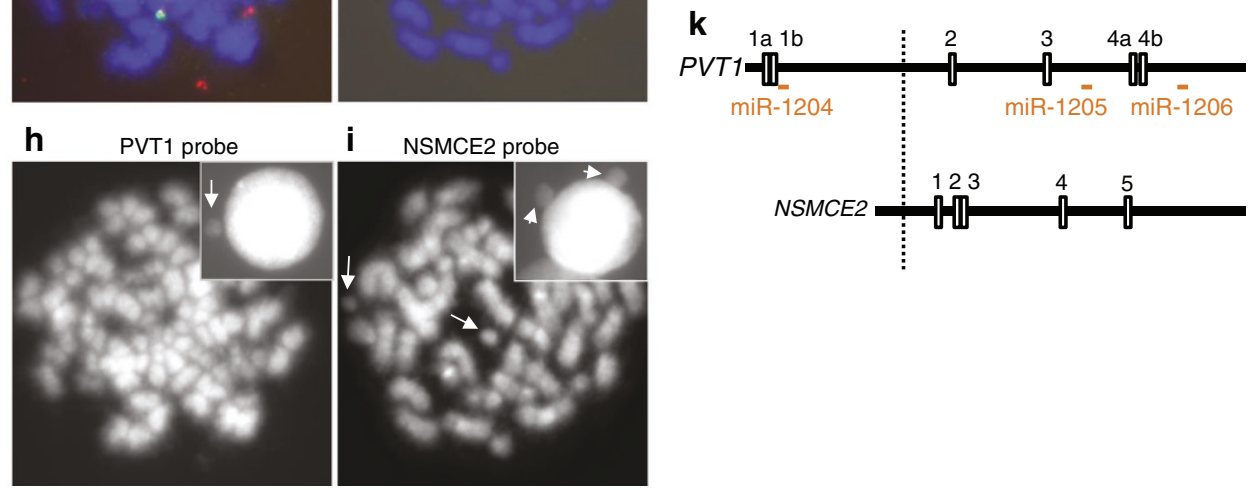

Figure 1 Identification of PVT1-NSMCE2 in the leukemic patient cells. (a) G-banding analysis. Arrow indicates two marker chromosomes (mars). (b) SKY analysis for the patient identified two mars derived from chromosome 8 (arrows). (c) Copy number changes at 8q24 detected by high-resolution oligonucleotide array. NSMCE2, TRIB1, MYC, PVT1, CCDC26, GSDMC, and FAM49B are amplified. The direction of the arrows reflects the direction of gene transcription. NG: no gene. (d) Detection of three PVT1-NSMCE2 fusion transcripts by RT-PCR. Primers were P1S and NSMCE2-Ex4AS for 5'-PVT1-NSMCE2-3'. Lane Pt.1: leukemic cells from the patient; lane N: water; lane M: size marker. (e) Sequence analysis of NSMCE2 fusion transcript in the patient. (f) FISH finding of the patient using PVT1 probe. Multiple red signals indicate extrachromosomal amplification of $5^{\prime} P V T 1$ on dmins. Co-localized red and green signals indicate normal PVT1. Inset shows 5'PVT1 amplification in a micronucleus equivalent of mar (arrow). (Additional file 5: Figure S3) (g) FISH finding from the patient using an NSMCE2 probe. Intense yellow signals indicate amplification of NSMCE2 on mars and co-localized red and green signals signify normal NSMCE2 on chromosome 8. Inset shows NSMCE2 amplification in a micronucleus equivalent of mar (arrow). (h and i) DAPI pictures of metaphase cells corresponding to (f) and (g). Arrows indicate mars. In metaphase, NSMCE2 amplification was detectable on mars. 5'PVT1 amplification were observed on dmins, however, PVT1 FISH probe sets could not identify mars because of the background dmins (f and h). (j) Results of LDI-PCR. Primers were NSM38374 and NSM38666 for 5'-PVT1-NSMCE2-3'. Lane Pt.1: leukemic cells from the patient; lane N: water; lane M: size marker. (Additional file 4: Table S2) (k) Genomic mapping of PVT1 and NSMCE2 exons and breakpoint. White vertical boxes represent exons; dotted line represents breakpoint of PVT1 and NSMCE2 in the patient detected by LDI-PCR. Horizontal line indicates the location of miRNAs. 

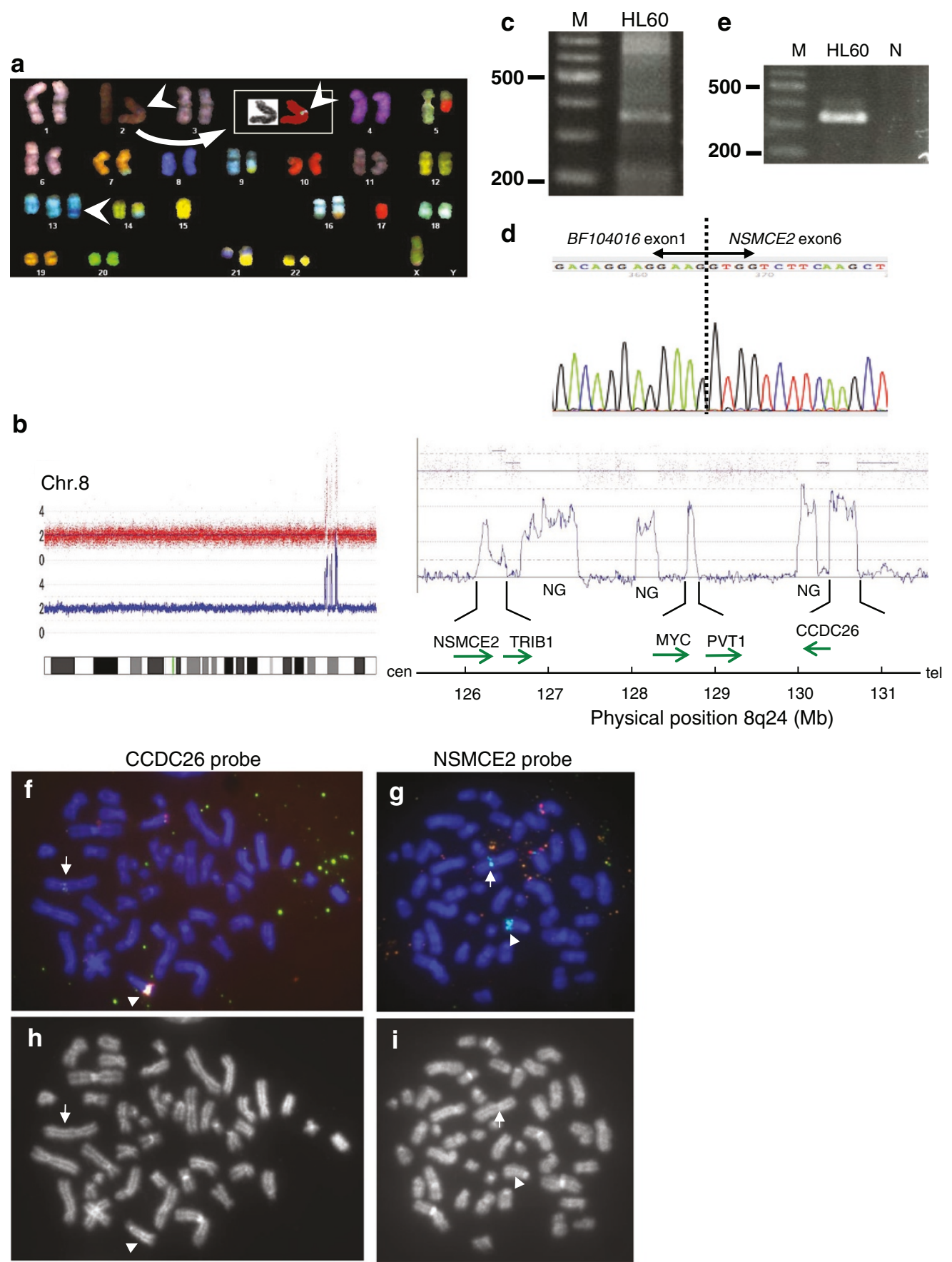

Figure 2 Identification of BF104016-NSMCE2 in HL60. (a) Representative SKY karyotype of HL60 cells. Arrowheads indicate material inserted from chromosome 8 on ins(2;8) and der(13)hsr(8). Inset shows pseudocolor image of ins(2;8). (b) Copy number changes at $8 \mathrm{q} 24$ detected by high-resolution oligonucleotide array. NSMCE2, TRIB1, MYC, PVT1 and CCDC26 are amplified in HL60. The direction of the arrows reflects the direction of the gene transcription. NG: no gene. (c) Bubble PCR products detected by nested PCR using NVAMP1 and NSMCE2-Ex7AS for the first PCR, and NVAMP2 and NSM695 for the second. M: size marker. (d) Sequence analysis of NSMCE2 fusion transcript of HL60. (e) Detection of BF104016-NSMCE2 fusion transcripts by RT-PCR. Primers were BF104-1S and NSMCE2-Ex7AS for 5'-BF104016-NSMCE2-3'. Lanes N: water. (Additional file 4: Table S2) (f) FISH finding of HL60 using CCDC26 probe. Intense co-localized red and green signal indicates amplification of the CCDC26 gene on der(13)hsr(8) (arrowhead). A co-localized red and green signal is seen on ins(2;8) (arrow). Multiple green signals indicate amplification of the $5^{\prime} C C D C 26$ gene on dmins. Co-localized red and green signals show normal CCDC26. (g) FISH finding of HL60 using NSMCE2 probe. Intense green signals indicate amplification of 3'NSMCE2 on der(13)hsr(8) (arrowhead) and ins(2;8) (arrow). Multiple red and green signals indicate amplification of the NSMCE2 gene on dmins. Co-localized red and green signals indicate normal chromosomal NSMCE2. (Additional file 5: Figure S3) (h and i) DAPI pictures of metaphase cells corresponding to (f) and (g). Arrow and arrowhead indicate ins(2;8) and der(13)hsr(8), respectively. 
The present findings are consistent with previous studies demonstrating that segmental genome amplification of 8q24 contains recurrent PVT1 fusion genes, which might be generated by chromothripsis [2,3]. Both lncRNAs, PVT1 and CCDC26, harbor retroviral integration sites and are transcribed into multiple splice forms [4-6]. PVT1 overexpression is induced by $M Y C$ or $\mathrm{p} 53$, contributing to suppression of apoptosis [7-9], whereas PVT1 produces six annotated microRNAs that have been implicated in oncogenesis $[3,10,11]$. The chimeric transcripts involving PVT1 may also regulate the expression of as-yet unspecified target genes through "enhancer-like functions" [12]. $C C D C 26$ amplification has been also identified as a recurrent abnormality that is associated with the response to retinoic acid-induced differentiation in AML [1,11,13-16]. This study is the first to identify NSMCE2-associated fusion genes in AML [17-19]. Knockdown of NSMCE2 induces chromosomal instability and increases the frequency of chromosomal breakage and loss [20]. We speculate that NSMCE2 gene rearrangement may potentially influence its function. Collectively, our study identified novel PVT1-NSMCE2 and CCDC26-NSMCE2 fusion genes that may play functional roles in leukemia.

\section{Additional files}

\section{Additional file 1: Supplementary material information.}

Additional file 2: Table S1. CNAG analysis of the region between the MTDH and LRRC6 genes on 8q24 in patient 1 with marker chromosomes. Results show the genomic size of the eight amplified segments that were selected based on the existence of known genes within them and their approximate positions.

Additional file 3: Figure S1. Association between $C C D C 26$ and BF104016 at 8q24.21. The scale indicates the region 8q24.21. White boxes and grey boxes indicate exons of CCDC26 and BF104016 on the genetic locus at 8q24.21, respecitively. Vertical black lines indicate exons on the CCDC26 isoform. According to the NCBI database, isoform 1 (BC070152.1) consists of four (1-2-3-4) exons, and isoform 2 (BC026098.1) consists of three (1a-3-4) exons. BF104016 consists of 2 exons. The sequence of BF104016 exon 2 is partly consistent with that of CCDC26 exon 4. ORF: hypothetical open reading frame.

Additional file 4: Table S2. Sequences of the primers used in this study.

Additional file 5: Figure S3. Identification of breakpoints region at 8 q24 by FISH. Upper panel: location of FISH probes shown as color bars and position of NSMCE2, TRIB1, MYC, and PVT1 genes at 8q24. Vertical black lines indicate exons of NSMCE2, PVT1, and BF104016. Lower panel: mapping of breakpoint in leukemic cells of patient 1 and HL60. Gray boxes indicate amplified regions detected.

Additional file 6: Figure S2. Expression of NSMCE2 in patient 1 and AML-derived cell lines. (a) NSMCE2 mRNA levels measured by RQ-PCR $(n=3$, mean $\pm S D)$. Theoretically, the NSMCE2 $7-8$ primer/probe can amplify both normal and aberrant NSMCE2 transcripts, while the NSMCE2 2-3 primer/probe set which can amplify only normal NSMCE2 transcript. NSMCE2 mRNA levels were normalized to $\beta$-actin and are relative to the control mRNA extracted from normal BM cells. NSMCE2 mRNA levels amplified by the NSMCE2 7-8 primer/probe set are higher than those amplified by the NSMCE2 2-3 primer/probe set in patient 1, HL60 and KG1 cells. (b) Protein analysis using the anti-NSMCE2 antibody in cells. Blot for $\beta$-actin was used as loading control. Lane 1: normal BM; lane 2:
KG1; lane 3: HL60. (c and d) IHC analysis of NSMCE2 expression in BM of patient 1 (c) and normal BM (d). NSMCE2 expression of leukemic cells was not higher than that of normal BM cells. Monocytes and megakaryocytes showed strong positive signals in their cytoplasm.

\section{Abbreviations}

dmins: Double minute chromosomes; hsr: Homogeneously staining regions; FISH: Fluorescence in situ hybridization; IncRNAs: Long noncoding RNAs; AML: Acute myeloid leukemia; MDS: Myelodysplastic syndromes; NSMCE2: Non-SMC element 2; SKY: Spectral karyotyping; RT-PCR: Reverse transcription-polymerase chain reaction; LDI-PCR: Long-distance inverse PCR.

\section{Competing interests}

The authors declare that they have no competing interests.

\section{Authors' contributions}

YC, JK and MT reviewed the literature and wrote the paper. YC, MYS, SM, and $\mathrm{SH}$ treated the patient. NS, HN, TT, SM, ST, TT, YS, TK, YM and MT collected the data. YC and NS performed the molecular analyses. YC, JK and MT contributed to the design of this study, final data analysis and edited the manuscript. All authors read and approved the final manuscript.

\section{Acknowledgements}

The authors thank Akari Kazami and Yoko Yamane for their expert technical assistance. This study was performed as a research program of the Project for Development of Innovative Research on Cancer Therapeutics (P-Direct), Ministry of Education, Culture, Sports, Science and Technology of Japan, and supported by a Grant-in-Aid for Cancer Research from the Ministry of Health, Labor and Welfare of Japan, by a Grant-in-aid for Scientific Research (B) and (C) from the Ministry of Education, Culture, Sports, Science and Technology of Japan, and by the National Cancer Center Research and Development Fund.

\section{Author details}

'Division of Hematology and Oncology, Department of Medicine, Kyoto Prefectural University of Medicine, Graduate School of Medical Science, 465 Kajii-choKamigyo-ku, Kyoto 602-8566, Japan. ${ }^{2}$ Department of Molecular Diagnostics and Therapeutics, Kyoto Prefectural University of Medicine, Graduate School of Medical Science, Kyoto, Japan.

Received: 2 September 2014 Accepted: 11 September 2014 Published online: 23 September 2014

\section{References}

1. Hirano T, Ike F, Murata T, Obata Y, Utiyama H, Yokoyama KK: Genes encoded within $8 q 24$ on the amplicon of a large extrachromosomal element are selectively repressed during the terminal differentiation of HL-60 cells. Mutat Res 2008, 640:97-106.

2. Campbell PJ, Stephens PJ, Pleasance ED, O'Meara S, Li H, Santarius T, Stebbings LA, Leroy C, Edkins S, Hardy C, Teague JW, Menzies A, Goodhead I, Turner DJ, Clee CM, Quail MA, Cox A, Brown C, Durbin R, Hurles ME, Edwards PA, Bignell GR, Stratton MR, Futreal PA: Identification of somatically acquired rearrangements in cancer using genome-wide massively parallel paired-end sequencing. Nat Genet 2008, 40:722-729.

3. Northcott PA, Shih DJ, Peacock J, Garzia L, Morrissy AS, Zichner T, Stütz AM, Korshunov A, Reimand J, Schumacher SE, Beroukhim R, Ellison DW, Marshall CR, Lionel AC, Mack S, Dubuc A, Yao Y, Ramaswamy V, Luu B, Rolider A, Cavalli FM, Wang X, Remke M, Wu X, Chiu RY, Chu A, Chuah E, Corbett RD, Hoad GR, Jackman SD, et al: Subgroup-specific structural variation across 1,000 medulloblastoma genomes. Nature 2012, 488:49-56.

4. Graham M, Adams JM, Cory S: Murine T lymphomas with retroviral inserts in the chromosomal 15 locus for plasmacytoma variant translocations. Nature 1985, 314:740-743.

5. Lemay G, Jolicoeur P: Rearrangement of a DNA sequence homologous to a cell-virus junction fragment in several Moloney murine leukemia virus-induced rat thymomas. Proc Natl Acad Sci USA 1984, 81:38-42.

6. Villeneuve L, Rassart E, Jolicoeur P, Graham M, Adams JM: Proviral integration site Mis-1 in rat thymomas corresponds to the pvt-1 translocation breakpoint in murine plasmacytomas. Mol Cell Biol 1986, 6:1834-1837. 
7. Guan Y, Kuo WL, Stilwell JL, Takano H, Lapuk AV, Fridlyand J, Mao JH, Yu M, Miller MA, Santos JL, Kalloger SE, Carlson JW, Ginzinger DG, Celniker SE, Mills GB, Huntsman DG, Gray JW: Amplification of PVT1 contributes to the pathophysiology of ovarian and breast cancer. Clin Cancer Res 2007 13:5745-5755.

8. Carramusa L, Contino F, Ferro A, Minafra L, Perconti G, Giallongo A, Feo S: The PVT-1 oncogene is a Myc protein target that is overexpressed in transformed cells. J Cell Physiol 2007, 213:511-518.

9. Barsotti AM, Beckerman R, Laptenko O, Huppi K, Caplen NJ, Prives C: p53-Dependent induction of PVT1 and miR-1204. J Biol Chem 2012, 287:2509-2519.

10. Beck-Engeser GB, Lum AM, Huppi K, Caplen NJ, Wang BB, Wabl M: Pvt1-encoded microRNAs in oncogenesis. Retrovirology 2008, 5:4

11. Huppi K, Volfovsky N, Runfola T, Jones TL, Mackiewicz M, Martin SE, Mushinski JF, Stephens R, Caplen NJ: The identification of microRNAs in a genomically unstable region of human chromosome $8 \mathrm{q} 24$. Mol Cancer Res 2008, 26:212-221.

12. Ørom UA, Derrien T, Beringer M, Gumireddy K, Gardini A, Bussotti G, Lai F, Zytnicki M, Notredame C, Huang Q, Guigo R, Shiekhattar R: Long noncoding RNAs with enhancer-like function in human cells. Cell 2010, 143:46-58.

13. Radtke I, Mullighan CG, Ishii M, Su X, Cheng J, Ma J, Ganti R, Cai Z, Goorha S, Pounds SB, Cao X, Obert C, Armstrong J, Zhang J, Song G, Ribeiro RC, Rubnitz JE, Raimondi SC, Shurtleff SA, Downing JR: Genomic analysis reveals few genetic alterations in pediatric acute myeloid leukemia. Proc Natl Acad Sci USA 2009, 106:12944-12949.

14. Guttman M, Amit I, Garber M, French C, Lin MF, Feldser D, Huarte M, Zuk O, Carey BW, Cassady JP, Cabili MN, Jaenisch R, Mikkelsen TS, Jacks T, Hacohen N, Bernstein BE, Kellis M, Regev A, Rinn JL, Lander ES: Chromatin signature reveals over a thousand highly conserved large non-coding RNAs in mammals. Nature 2009, 458:223-227.

15. Kühn MW, Radtke I, Bullinger L, Goorha S, Cheng J, Edelmann J, Gohlke J, Su X, Paschka P, Pounds S, Krauter J, Ganser A, Quessar A, Ribeiro R, Gaidzik VI, Shurtleff S, Krönke J, Holzmann K, Ma J, Schlenk RF, Rubnitz JE, Döhner K, Döhner $H$, Downing JR: High-resolution genomic profiling of adult and pediatric core-binding factor acute myeloid leukemia reveals new recurrent genomic alterations. Blood 2012, 119:e67-75.

16. Yin W, Rossin A, Clifford JL, Gronemeyer H: Co-resistance to retinoic acid and TRAIL by insertion mutagenesis into RAM. Oncogene 2006, 25:3735-3744

17. Brown J, Bothma H, Veale R, Willem P: Genomic imbalances in esophageal carcinoma cell lines involve Wnt pathway genes. World J Gastroenterol 2011, 17:2909-2923.

18. Parisi F, Ariyan S, Narayan D, Bacchiocchi A, Hoyt K, Cheng E, Xu F, Li P, Halaban R, Kluger $Y$ : Detecting copy number status and uncovering subclonal markers in heterogeneous tumor biopsies. BMC Genomics 2011, $12: 230$.

19. Camps J, Nguyen QT, Padilla-Nash HM, Knutsen T, McNeil NE, Wangsa D, Hummon AB, Grade M, Ried T, Difilippantonio MJ: Integrative genomics reveals mechanisms of copy number alterations responsible for transcriptional deregulation in colorectal cancer. Genes Chromosomes Cancer 2009, 48:1002-1017.

20. Rai R, Varma SP, Shinde N, Ghosh S, Kumaran SP, Skariah G, Laloraya S: Small ubiquitin-related modifier ligase activity of Mms21 is required for maintenance of chromosome integrity during the unperturbed mitotic cell division cycle in Saccharomyces cerevisiae. J Biol Chem 2011, 286:14516-14530.

doi:10.1186/s13045-014-0068-2

Cite this article as: Chinen et al:: 8 q24 amplified segments involve novel fusion genes between NSMCE2 and long noncoding RNAs in acute myelogenous leukemia. Journal of Hematology \& Oncology 2014 7:68.

\section{Submit your next manuscript to BioMed Central and take full advantage of:}

- Convenient online submission

- Thorough peer review

- No space constraints or color figure charges

- Immediate publication on acceptance

- Inclusion in PubMed, CAS, Scopus and Google Scholar

- Research which is freely available for redistribution
C Biomed Central 